Radiologist. Over the course of 16 days, 21 litres was drained with reduction in abdominal distension and leg oedema; her mobility and quality of life improved. To support management at home, Ms X's mother learned to perform the drainage independently. Bloods were monitored weekly and she was readmitted for IV albumin when blood albumin fell to $22 \mathrm{~g} / \mathrm{l}$.

The volume of ascites drained gradually reduced to nothing and the drain was removed due to concerns about infection after sepsis developed. The ascites did not recur and Ms X had no further admissions for decompensation of CCF. She died at home 10 weeks after the drain removal

Conclusion Permanent ascitic drain insertion can reduce diuretic use and frequency of decompensations in patients with large volume cardiac ascites.

\section{THE USE OF OPIOIDS IN SYRINGE DRIVERS: AN AUDIT ACROSS 2 SPECIALIST PALLIATIVE CARE SERVICES IN THE EAST MIDLANDS REGION}

Rebecca Robinson, Alpna Chauhan, Ruth England. Rebecca Boyland. John Eastwood Hospice, Mansfield, Royal Derby Hospital

\subsection{6/spcare-2021-PCC.153}

Background There has been a recent increase in concern regarding the use of opioid medications in syringe drivers following the publicised report of the Gosport Inquiry, 2018. In our own clinical practice we have seen an increased anxiety and caution regarding syringe drivers, particularly in the community.

Aim To identify the average starting dose of opioids in syringe drivers for patients known to the Specialist Palliative Care Teams (SPC) across three settings; hospice, hospital and community. John Eastwood Hospice, Mansfield was the initial site in 2018 and a similar audit was conducted at Royal Derby Hospital in 2019.

Standards Our standards were taken from a number of sources, including the Palliative Care Formulary. For patients already on opioids, total daily dose should be appropriately converted to the opioid being used in the driver; for an opioid na-ve patient, 10-20 $\mathrm{mg}$ morphine is suggested. Clinical judgement based on the patient's individual needs is vital.

Method Patients commenced on a syringe driver with an opioid across a 2-month period were identified; retrospectively in Mansfield, prospectively in Derby. Retrospective case note review was carried out using electronic and/or paper records.

Results The average (mean) starting dose of opioid in a syringe driver (morphine subcutaneous equivalent) prescribed or advised by SPC was $27 \mathrm{mg}$ (range $2.5 \mathrm{mg}-160 \mathrm{mg}$ ) in Mansfield, $21 \mathrm{mg}$ (range $3.75 \mathrm{mg}-80 \mathrm{mg}$ ) in Derby. All patients had a documented indication for both the use of an opioid and use of a syringe driver. Doses used were comparable to opioid use in the preceding 24 hours.

Conclusions The results from these audits are reassuring; demonstrating that when opioids in syringe drivers are used, the indication is considered, doses used are small compared to standards, and in the majority it is beneficial. The results between sites were similar, suggesting that practice is consistent across different areas of the region.

\section{A REVIEW OF THE USE OF MUCOLYTIC AGENTS IN MOTOR NEURONE DISEASE (MND). IS THERE BENEFIT TO USING MULTIPLE AGENTS OVER MONO-THERAPY?}

Claire Stockdale, Richard Price, Trish Campbell, Lisa Siewwright. Severn Hospice Shrewsbury, Health Education England (West Midlands)

\subsection{6/spcare-2021-PCC.154}

Background/Aims In MND, progressive bulbar and diaphragmatic weakness cause weak cough and difficulty expectorating. This can cause difficulty in managing the amount of saliva produced, which can lead to sore skin, wet clothes, embarrassment and precipitation of choking episodes. Thicker sputum can compound this issue. Mucolytics can be useful here, however guidelines for their use tend to be based around anecdotal experience rather than using higher level evidence. This particularly applies to the use of multiple mucolytics. We aimed to learn more about the benefits and harms of multiple mucolytic therapy versus single mucolytic therapy in MND. We hoped to develop a guideline outlining when each, or multiple, agents are appropriate in MND.

Methods We reviewed the notes of all patients with MND under the care of a Shropshire Palliative Care Team over a one year period and identified those on multiple mucolytic therapy. We noted outcomes of symptom improvement and side effects reported following initiation of multiple mucolytic therapy.

Results Of 64 patients identified, 32 patients required mucolytic therapy, with $31 / 32$ being started on Carbocisteine initially. Of these, $12 / 32(37.5 \%)$ went on to receive multiple mucolytics. Symptom improvement was reported in $2 / 12$ $(16.67 \%)$ with multiple mucolytic therapy - in both cases the benefit followed the addition of Erdosteine. Worsening of symptoms was reported in $1 / 12(8.33 \%)$ patients. In $9 / 12(75 \%)$ patients, there was either no symptom improvement or no data describing outcomes.

Conculsions In most patients receiving multiple mucolytic there was either no symptom improvement or no recorded evidence of outcome. Where multiple mucolytic therapy is used, Erdosteine may be the most effective second line agent, however larger numbers are needed to determine this. Prospective research to collect outcome data to assess the effect of mucolytic therapy in a wider cohort of patients with MND would be useful in ascertaining more definitive conclusions.

\section{IMPROVING SAFETY OF OPIOID PRESCRIBING AND ADMINISTRATION ON A HOSPICE INPATIENT UNIT (IPU)}

Sarah Longwell, Maria Cassidy, Salma Laila. Marie Curie Hospice, Bradford

\subsection{6/spcare-2021-PCC.155}

Introduction Opioids are commonly used drugs in palliative care, in both healthcare and community settings. The risk for harm from these drugs means that they are subject to additional regulations and good prescribing practice should be followed. NICE guidance on safe prescribing practice recommends that decimal points should be avoided. There should be consideration that palliative care patients often have a significant tablet burden and there is increased risk for error 